\title{
Unmet needs in ankylosing spondylitis patients receiving tumour necrosis factor inhibitor therapy; results from a large multinational real-world study
}

\author{
A. Deodhar ${ }^{1 *}$, V. Strand ${ }^{2}$, P. G. Conaghan ${ }^{3}$, E. Sullivan ${ }^{4}$, S. Blackburn ${ }^{4}$, H. Tian ${ }^{5}$, K. Gandhi ${ }^{5}$, S. M. Jugl ${ }^{6}$ and R. Alten ${ }^{7}$
}

\begin{abstract}
Background: Symptoms and comorbidities of ankylosing spondylitis (AS) considerably reduce health-related quality of life (HRQoL) and ability to work. This real-world study assessed rates of tumour necrosis factor inhibitor (TNFi) use and switching, treatment failure, and associations between failing TNFi and HRQoL, work productivity and activity impairment (WPAI).

Methods: AS patients and their treating physicians completed questionnaires capturing patient demographics, clinical status, TNFi treatment history, reasons for switching TNFi, HRQoL and WPAl. Current TNFi was determined as "failing" if, after $\geq 3$ months, physician-rated disease severity had worsened, remained severe, was "unstable/ deteriorating", physicians were dissatisfied with disease control and/or did not consider treatment a "success".

Results: The analysis included 2866 AS patients from 18 countries. Of 2795 patients with complete treatment data, 916 (32.8\%) patients had never received TNFi therapy, 1623 (58.1\%) patients were receiving their 1st TNFi and 200 (7.2\%) patients had ever received $\geq 2$ TNFi (treatment switch). Primary or secondary lack of efficacy were the commonest reasons for switching, and the mean delay in switching after primary lack of efficacy was 11.1 months. 232 (15.4\%) patients on TNFi were currently "failing" who, compared to those with treatment success, reported poorer HRQoL: 5-dimension EuroQoL (EQ-5D-3 L): 0.63 vs. 0.78; Medical Outcomes Study Short-Form Health Survey version 2 (SF-36v2) mental component summary (MCS): 41.8 vs. 46.3; physical component summary (PCS): 40.2 vs. 45.1 ; impaired work productivity: $46.4 \%$ vs. $25.0 \%$; and activity: $44.5 \%$ vs. $29.6 \%$; all $P<0.001$.
\end{abstract}

Conclusions: Among AS patients, switching TNFi is uncommon and delayed by nearly 1 year despite primary lack of efficacy. Patients currently failing TNFi experience worse physical function, HRQoL and work productivity.

Keywords: Ankylosing spondylitis, DMARD, Quality of life, Tumour necrosis factor-alpha, Treatment failure

\section{Background}

Ankylosing spondylitis (AS) is characterized by inflammatory back pain, fatigue and joint swelling from axial and peripheral articular manifestations as well as comorbidities such as uveitis, inflammatory bowel disease, psoriasis and osteoporotic fractures which pose a significant burden to the patient $[1,2]$. In addition, spinal inflammation and structural damage can lead to stiffness

\footnotetext{
* Correspondence: deodhara@ohsu.edu

${ }^{1}$ Oregon Health and Science University, Portland, OR, USA

Full list of author information is available at the end of the article
}

or immobility from vertebral fusions [3]. These painful and often disabling clinical features have a detrimental effect on quality of life and mortality as well as burdening the patient and society with impaired ability to work, substantial healthcare costs and productivity loss [2, 4].

Early diagnosis is important to improve outcomes; however, diagnosis is often delayed from symptom onset by as much as 14 years in the USA and 6-8 years in Europe [5-7]. Diagnosis and treatment delays are correlated with increased radiological severity of AS $[5,8]$.

Primary pharmacologic treatment of AS are nonsteroidal anti-inflammatory drugs, with biological 
Disease Modifying Anti-Rheumatic Drugs (bDMARDs) such as tumour necrosis factor inhibitors (TNFi) as a first-line bDMARD option, and the interleukin (IL)-17A inhibitors secukinumab and ixekizumab recommended for patients who have failed TNFi treatment [9]. It is not uncommon for patients with AS to experience TNFi therapeutic failure. For example, in a longitudinal, observational study of 249 cases of AS patients treated with TNFi, these agents had been discontinued at 1 year in 56 (22.5\%) cases. Reasons for TNFi discontinuation included lack of efficacy and adverse events in 36.4 and $43.6 \%$ of cases, respectively [10]. Interestingly in this study, patients with RA had lower retention rates than patients with AS (65.4\% vs $77.5 \%$, respectively), which may reflect fewer options for alternative therapies in AS.

This multinational study was designed to describe use and switching of TNFi in AS patients; to assess rates of current TNFi failures and the associations of failing TNFi treatment with patient-reported health-related quality of life (HRQoL), work productivity and activity impairment (WPAI) using real-world data.

\section{Methods}

The present study analysed data acquired from the Adelphi AS Disease Specific Program ${ }^{\text {Tx }}$ (DSP) from 2015 to 2016 in the following 18 countries: the USA, Canada (North America), Brazil, Mexico (LatAm), France, Germany, Italy, Spain, the UK (EU5), Japan, Malaysia, South Korea, Taiwan, Australia (APAC), Turkey, Egypt, Saudi Arabia and the United Arab Emirates (T\&ME). DSPs are large multinational point-in-time surveys designed to identify current disease management, and both patient- and physician-reported disease impact from real-world clinical practice settings [11]. The DSP was conducted in line with contemporary legislation, namely the US Health Insurance Portability and Accountability Act 1996 [12] and the Health Information Technology for Economic and Clinical Health Act legislation [13]. DSPs also comply with relevant market research guidelines and legal obligations. Data collection was performed in accordance with the European Pharmaceutical Marketing Research Association guidelines and ethics committee approval was therefore not required [14]; i.e. DSPs are non-interventional and no personally identifiable protected health information is extracted, though all patients who participated provided informed consent.

\section{Patients and physicians}

Eligible patients were adults over 18 years of age, had a physician-confirmed diagnosis of AS, were not currently involved in a clinical trial and visited a participating physician. Eligible physicians (rheumatologists, and orthopedists and internists in Japan) were those who were treating AS patients and practicing $\geq 3$ years.
Participating physicians completed a questionnaire for 1 to 8 consecutive AS patients. Physicians reported patient demographics, clinical assessments, medication use and treatment history; responses were based on data available from treatment records. Patients were then invited to complete a voluntary patient-reported questionnaire. The questionnaires included the 5-dimension EuroQoL (EQ-5D-3 L) [15, 16], Medical Outcomes Study Short-Form Health Survey version 2 (SF-36v2) [17, 18] and WPAI General Health [19]. Questionnaires were completed independently from physicians and returned in sealed envelopes to ensure confidentiality.

\section{Definitions}

To be eligible for assessment of treatment response patients had to be exposed to a TNFi $\geq 3$ months. "TNFi switching" was defined as a change from one TNFi to another. The reasons for switching from 1st to 2nd TNFi were selected by physicians from a list of choices including primary lack of efficacy (initial non-response) or secondary lack of efficacy (loss of response over time), patient change (improvement, worsening of condition), lack of tolerability, patient preference, administrative reasons (i.e. formulary requirements) and physician preference for an alternative therapy; Fig. 1 provides the full list of options; no additional explanation of the options were provided so results represent physicians' real-world interpretation of reasons.

Patients were defined as "failing TNFi" if, after $\geq 3$ months of treatment with their current TNFi therapy, at least one of the following criteria (assessed by the treating physician) was met: disease severity (mild, moderate or severe) had worsened or remained severe; disease activity (improving, stable, unstable or deteriorating) was unstable or deteriorating; or physician reported dissatisfaction with current control of AS. Any patient not defined as "failing TNFi" was defined as "TNFi success".

\section{Statistical analyses}

Analyses were performed at both global and regional levels. Categorical variables are presented as counts and proportion of respondents. Continuous numerical variables are presented as means and standard deviations (SD). Pearson's $X^{2}$ test was used to evaluate differences in failure rates by lines of TNFi.

Patient characteristics were analyzed descriptively and included demographics (age, gender and Body Mass Index [BMI]), human leukocyte antigen B27 (HLA-B27) status, number of TNFi therapies ever received, duration patients remained on 1st TNFi before switching, reasons for switching from 1st to 2nd TNFi, and proportions of patients currently failing TNFi overall and at each line of therapy. 


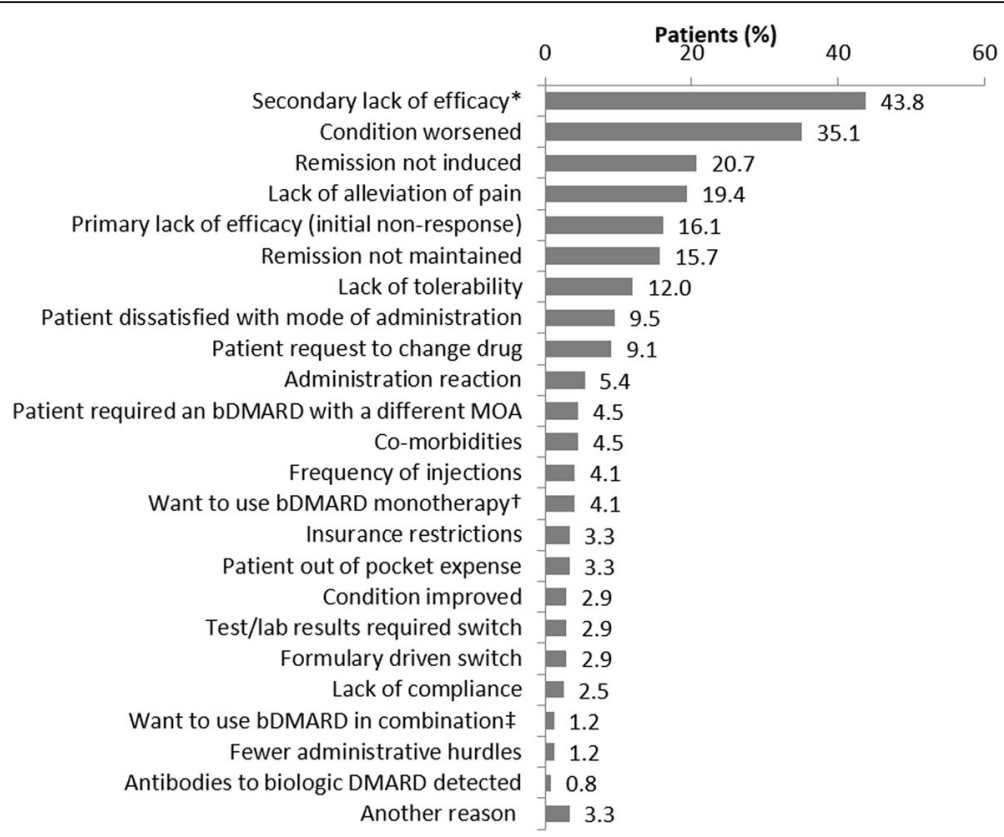

Fig. 1 Physician-reported reasons given for patient switching from 1st to 2nd line TNFi. * Secondary lack of efficacy: loss of response over time; $\dagger$ I wanted to use bDMARD that can be used as a monotherapy; $\neq$ I wanted to use a bDMARD that can be used in combination. MOA: Mode of action; bDMARD: biologic Disease Modifying Anti Rheumatic Drug

Linear regression analyses were used for EQ-5D-3 L, SF-36v2 (physical component summary [PCS] and mental component summary $[\mathrm{MCS}])$ scores and WPAI. Treatment response (failing TNFi or TNFi success) was the independent variable; differences in age, gender, BMI, smoking status, time since symptom onset and region were controlled for. Predicted values for all outcomes were subsequently stratified by TNFi failure or success. All other variables were fixed at their means.

Stata Statistical Software: Release 15 (StataCorp LP, College Station, TX) was used for all analyses.

\section{Results}

\section{Patients characteristics}

Six-hundred and forty physicians (North America, $n=$ 97; LatAm, $n=31$; EU5, $n=299$; APAC, $n=115$; T\&ME, $n=98$ ) and 2866 AS patients (North America, $n=538$; LatAm, $n=139$; EU5, $n=1512$; APAC, $n=353$; T\&ME, $n=324$ ) from 18 countries participated in the study; 1406 patients (49\%) completed the voluntary patient questionnaires including EQ-5D-3 L $(n=1382), \mathrm{SF}-36 \mathrm{v} 2$ $(n=1402)$ and WPAI $(n=1352)$.

Patient characteristics such as mean age, BMI, time since diagnosis, Bath Ankylosing Spondylitis Disease Activity Index (BASDAI) and Bath Ankylosing Spondylitis Functional Index were similar across most regions, although differences were noted mostly in T\&ME patients (see Additional file 1: Table S1). In T\&ME patients, mean age was $<40$ years (37.5 years), whereas in all other regions the mean age was $>40$ years. Mean time since symptom onset ranged from 2.8 years in T\&ME to 10.8 years in North America, and mean time since diagnosis ranged from 1.5 years in T\&ME to 7.3 years in North America. The proportion of patients classified as "severe" by their treating physician ranged from $3.6 \%$ in Latin America to $7.7 \%$ in T\&ME. Median BASDAI scores ranged from 2.5 in T\&ME to 4.0 in North America for the subset of patients in whom data was available.

\section{TNFi use and switching}

Of the 2795 (of 2866) patients with complete treatment data, 916 (32.8\%) had never received a TNFi, 1623 (58.1\%) had received one, 200 (7.2\%) two, and 56 (2.0\%) three or more TNFi (Table 1). The mean (SD) disease durations for these groups of patients were 4.4 (7.2), 6.3 (7.3), 9.5 (7.7) and 13.0 (8.0) years, respectively.

In 242 patients where information for switching from 1st to 2nd TNFi therapy was available, the commonest reason was lack of efficacy in over half of patients. Secondary lack of efficacy (loss of response over time) was reported in $106(43.8 \%)$ patients, and primary lack of efficacy (initial non-response) in 39 patients (16.1\%) (Fig. 1). Other reasons for switching from 1st TNFi therapy were "condition worsened" $(n=85 ; 35.1 \%)$, "remission not induced" $(n=50 ; 20.7 \%)$, "lack of alleviation of pain" $(n=47 ; 19.4 \%)$ and "remission not maintained" ( $n=38 ; 15.7 \%)$. 
Table 1 Patient TNFi therapy exposure and bDMARD switching

\begin{tabular}{|c|c|c|c|c|c|c|}
\hline & $\begin{array}{l}\text { All } \\
(n=2795)\end{array}$ & $\begin{array}{l}\text { North America } \\
(n=530)\end{array}$ & $\begin{array}{l}\text { LatAm } \\
(n=137)\end{array}$ & $\begin{array}{l}\text { EU5 } \\
(n=1478)\end{array}$ & $\begin{array}{l}\text { APAC } \\
(n=335)\end{array}$ & $\begin{array}{l}\text { T\&ME } \\
(n=315) \\
\end{array}$ \\
\hline \multicolumn{7}{|l|}{$\begin{array}{l}\text { Number of previous TNFi therapies ever } \\
\text { received, } n(\%)\end{array}$} \\
\hline 0 & 916 (32.8) & $108(20.4)$ & 15 (10.9) & $535(36.2)$ & $103(30.7)$ & $155(49.2)$ \\
\hline 1 & $1623(58.1)$ & $347(65.5)$ & $113(82.5)$ & $821(55.5)$ & $194(57.9)$ & $148(47.0)$ \\
\hline 2 & $200(7.2)$ & $60(11.3)$ & $9(6.6)$ & $89(6.0)$ & $31(9.3)$ & $11(3.5)$ \\
\hline $3+$ & $56(2.0)$ & $15(2.8)$ & $0(0.0)$ & $33(2.2)$ & $7(2.1)$ & $1(0.3)$ \\
\hline $\begin{array}{l}\text { Time on 1st bDMARD despite primary lack of } \\
\text { efficacy, months }\end{array}$ & $(n=34)$ & $(n=16)$ & & $(n=13)$ & $(n=2)$ & $(n=3)$ \\
\hline Mean (SD) & $11.1(10.2)$ & $12.6(11.6)$ & - & $10.7(9.7)$ & $1(0.0)$ & $11.3(5.0)$ \\
\hline Median & 9.5 & 11.0 & - & 9.0 & 1.0 & 12.0 \\
\hline Min, Max & $0.0-36.0$ & $2.0-36.0$ & - & $0.0-36.0$ & $1.0-1.0$ & $6.0-16.0$ \\
\hline IQR & $0.0,1.0$ & $0.0,1.5$ & $0.0,0.0$ & $0.0,1.0$ & $0.0,0.5$ & $0.0,0.0$ \\
\hline
\end{tabular}

Abbreviations: APAC Asia Pacific region, $6 D M A R D$ biological disease modifying anti-rheumatic drug; BMI body mass index, EU5 European Union 5, IQR interquartile range, LatAm Latin America, T\&ME Turkey and Middle East, SD standard deviation, TNFi tumour necrosis factor inhibitor

Information on treatment duration was available for 34 of the 39 patients who switched therapy due to primary lack of efficacy. These patients remained on the failed therapy for a mean (SD) of 11.1 months (10.2) before treatment was switched. The longest reported time to switch was 36 months (Table 1).

\section{Patients currently "failing TNFi"}

Treatment success or failure was evaluated in 1507/2866 patients. A total of 916 patients were excluded as they had never received TNFi, 90 were not currently receiving TNFi, 182 were exposed to TNFi $<3$ months, 100 had missing duration of TNFi treatment data and 71 had other missing treatment data. Globally, 232 (15.4\%) patients were failing current TNFi according to the definitions provided and failure rates were higher with each successive TNFi. Among patients with data available on the number of TNFi ever received, $13.9 \%$ were failing their 1st TNFi. Globally, failure rates increased to $28.6 \%$ in patients receiving their 3rd (or later) TNFi $(P=$ 0.0089). In North America and EU5, 16.2\% (North America) and 10.3\% (EU5) of patients were failing 1st TNFi, and $36.4 \%$ (North America; $P=0.2062$ ) and $26.9 \%$ (EU5; $P=0.0111$ ) were failing their 3rd (or later) TNFi. For regions with lower patient numbers, the trend again increased with subsequent TNFi (either 2nd or 3rd, if available) (Fig. 2).

\section{Patient characteristics by failing TNFi and TNFi success groups}

With some exceptions, patient characteristics between failing and successful TNFi groups were similar in most regions (Table 2). Patients with treatment success were more likely male in EU5 but no other regions (Table 2). Globally, patients who were failing TNFi had more AS symptoms compared with TNFi successes (2.5 vs. 1.8, $P<0.0001$ ), as observed in North America (3.1 vs. 2.1; $P=0.0003)$, EU5 (2.4 vs. $1.6 ; P<0.0001)$ and APAC $(2.3$ vs. $1.8, P=0.0203$ ) but not in LatAm or T\&ME (Table 2). Globally, both erythrocyte sedimentation rate (ESR) (24.9 vs. $15.1 ; P<0.0001)$ and $C$-reactive protein (CRP) (7.2 vs. $4.5 ; P<0.0001$ ) levels were higher in patients failing compared with TNFi treatment success groups (Table 2).

\section{Association between failing current TNFi and HRQoL and WPAI}

Linear regression analysis exposed that failing treatment compared with treatment success was associated with a lower HRQoL, shown by the impact on the adjusted EQ-5D-3 L (0.63 vs. 0.78, coef. $-0.149, P<0.0001)$, and SF-36v2 PCS (40.2 vs. 45.1, coef. $-4.917, P<0.0001)$ and MCS scores (41.8 vs. 46.3, coef. $-4.511, P<0.0001)$ (Fig. 3a and b). All SF-36 domain scores were lower among patients failing TNFi treatment compared with those with treatment success (Fig. 4). Among those working, WPAI overall work productivity was confirmed as worse in patients failing vs. not failing (46.4\% vs. $25.0 \%$, coef. 21.397, $P<0.0001$ ), as was absenteeism (11.2\% vs. $5.1 \%$, coef. $6.035, P=0.007)$ and presenteeism (43.1\% vs. $22.4 \%$, coef. $20.758, P<0.0001$ ), and impairment in daily activities in the entire population $(44.5 \%$ vs. $29.6 \%$, coef. $14.961, P<0.0001$ ) (Fig. $3 c$ ).

\section{Discussion}

This real-world, large multinational study of TNFi use in patients with AS demonstrates that TNFi do not consistently deliver sustained efficacy; switching was mainly associated with primary and secondary treatment failures, i.e. primary and secondary lack of efficacy, and 


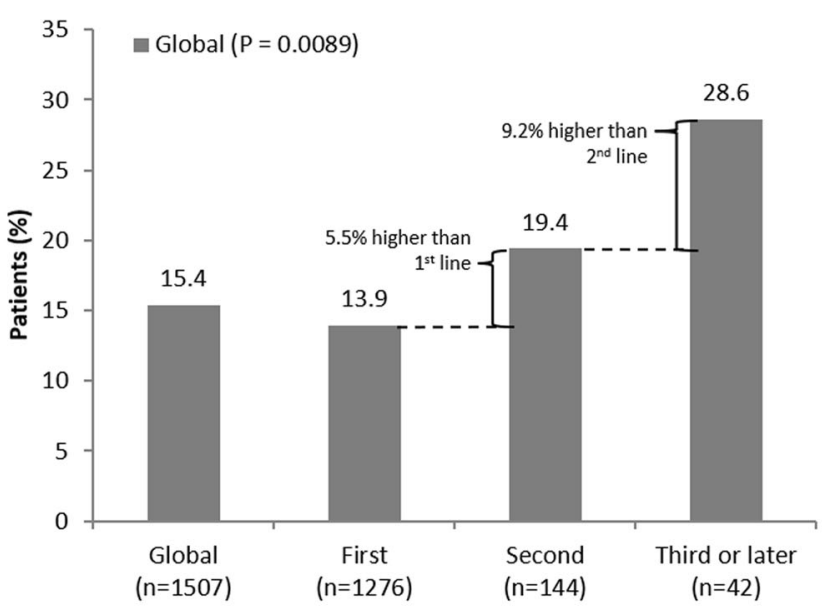

\begin{tabular}{|c|c|c|c|c|c|}
\hline $\begin{array}{l}\text { Global } \\
\qquad \% \text { Failing }\end{array}$ & $\begin{array}{c}(n=1507) \\
15.4 \\
\end{array}$ & $\begin{array}{c}(n=1276) \\
13.9\end{array}$ & $\begin{array}{c}(n=144) \\
19.4 \\
\end{array}$ & $\begin{array}{c}(n=42) \\
28.6 \\
\end{array}$ & 0.0089 \\
\hline North America & $(n=326)$ & $(n=265)$ & $(n=46)$ & $(n=11)$ & \\
\hline$\%$ Failing & 17.2 & 16.2 & 19.6 & 36.4 & $P=\mathrm{NS}$ \\
\hline LatAm & $(n=88)$ & $(n=79)$ & $(n=7)$ & $(n=0)$ & \\
\hline$\%$ Failing & 17.0 & 17.7 & 0.0 & - & $P=\mathrm{NS}$ \\
\hline EU5 & $(n=836)$ & $(n=708)$ & $(n=72)$ & $(n=26)$ & \\
\hline \% Failing & 12.3 & 10.3 & 16.7 & 26.9 & $P=0.0111$ \\
\hline APAC & $(n=156)$ & $(n=129)$ & $(n=17)$ & $(n=5)$ & \\
\hline$\%$ Failing & 28.2 & 27.1 & 35.3 & 20.0 & $P=\mathrm{NS}$ \\
\hline T\&ME & $(n=101)$ & $(n=95)$ & $(n=2)$ & $(n=0)$ & \\
\hline$\%$ Failing & 13.9 & 13.7 & 50.0 & - & $P=\mathrm{NS}$ \\
\hline
\end{tabular}

Fig. 2 Rates of TNFi failure on successive lines of TNFi therapy. APAC, Asia Pacific region; EU5, European Union 5; T\&ME, Turkey and Middle East

many patients were failing their current TNFi. Clinical responses to TNFi declined with each subsequent treatment, evidenced by a higher incidence currently failing their 2nd or 3rd TNFi. Our cross-sectional data analysis allows us to report the rates of patients currently failing therapy they are still taking, based on their clinical profile. This differs from previous studies [20-22], where failure rates were calculated based on the proportion of patients who switched therapy as an indicator of failure.

The most common reasons for switching in our study were secondary and primary lack of efficacy (43.8 and $16.1 \%$, respectively), worsening of condition (35.1\%), remission not induced or maintained (20.7 and 15.7\%, respectively), and lack of alleviation of pain (19.4\%) and lack of tolerability (12.0\%), consistent with previous reports $[23,24]$. Data reported in our study reflect physicians' responses, and thus their real-world reasoning for switching therapy, even though there may be potential overlaps in the responses. A recent review from 21 studies reported the most common reasons for switching to a 2nd TNFi were lack of efficacy (14-68\%), loss of efficacy (13-61\%) and adverse events/poor tolerability (13-57\%) [25]. Lack of efficacy or adverse events (AE) after the 1st TNFi may justify switching to another TNFi on the basis that they differ in structure, immunogenicity, half-life and administration schedules [23, 24]. This is supported by the common observation that patients who switched because of loss of response over time, due to adverse events or other reasons, were more likely to respond to a 2nd TNFi than patients with a primary (initial) lack of response [25].

In cases where physicians reported switching from 1st to 2nd TNFi therapy was due to primary lack of efficacy, time to switch to the 2nd TNFi occurred at 11.1 months on average. Our global findings are consistent with data from a retrospective analysis of patients treated with TNFi at two British hospitals where the mean duration of treatment prior to switching in patients with 
Deodhar et al. BMC Rheumatology

(2020) 4:19

Page 6 of 11

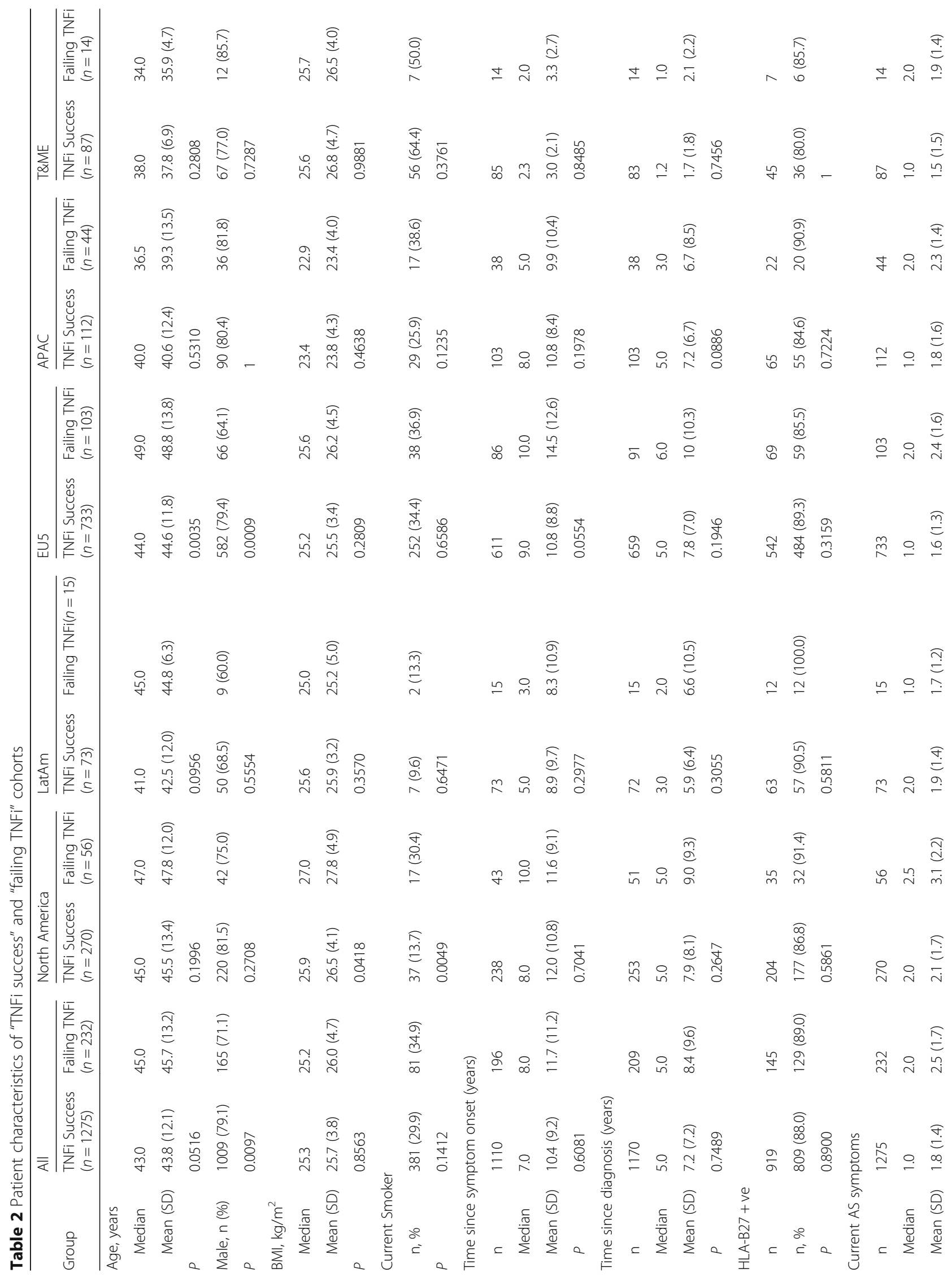




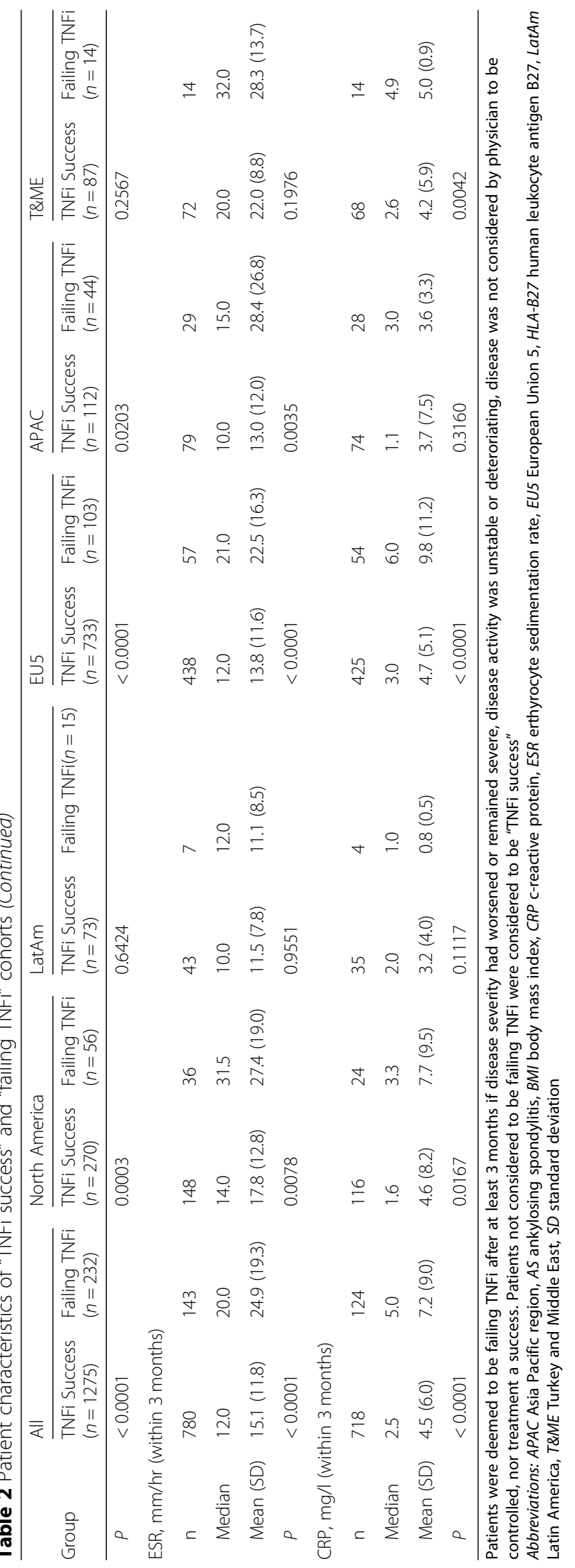




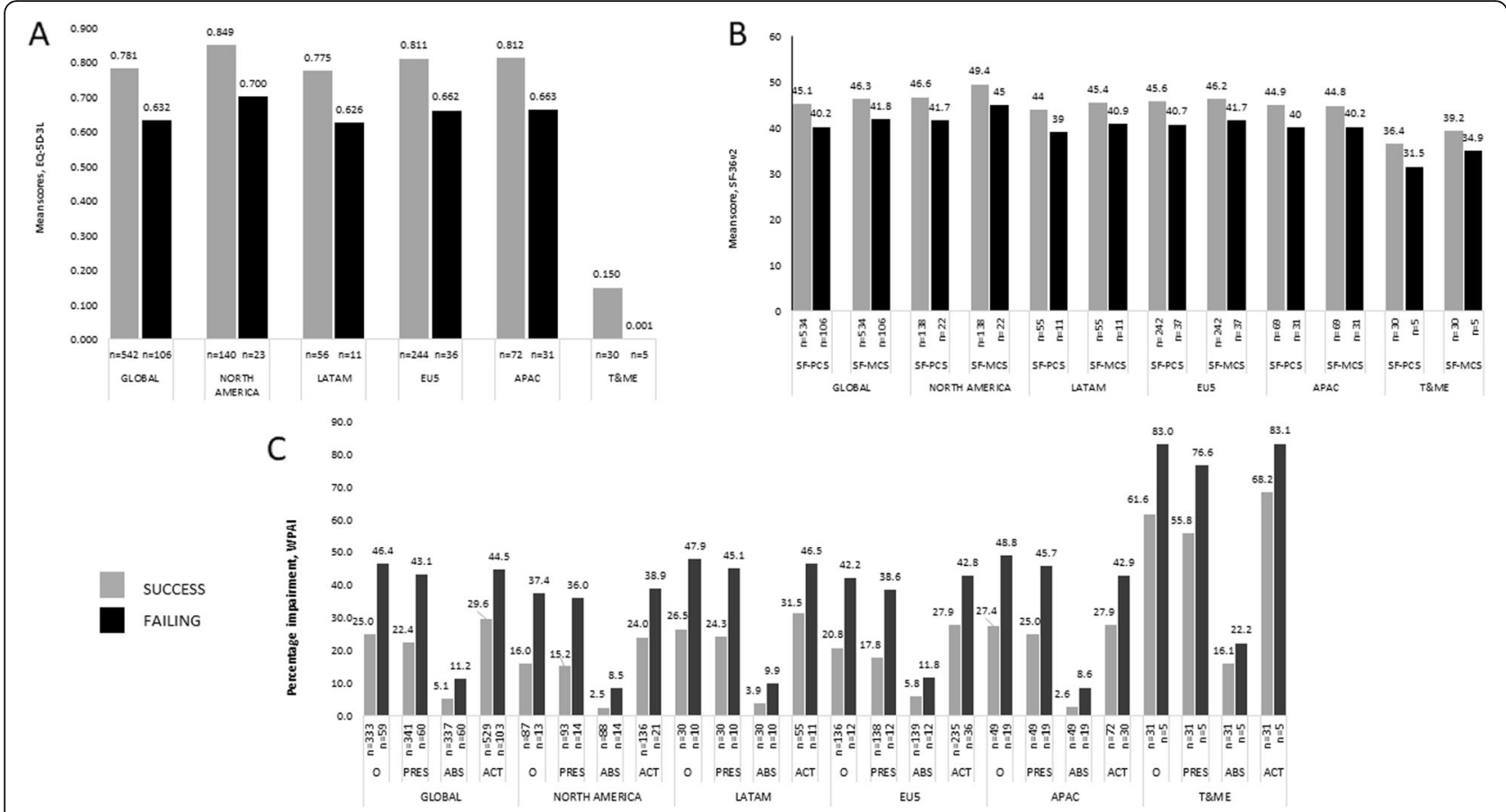

Fig. 3 Results are adjusted for age, gender, smoking status, BMI, time since onset of symptoms and region. ABS, absenteeism; ACT, activity impairment; APAC, Asia Pacific region; EU5, European Union 5; LatAm, Latin America; O, overall work impairment; PRES, presenteeism; SD, standard deviation; T\&ME, Turkey and Middle East. SF-PCS, $P<0.0001$; SF-MCS, $P=0.0004$; overall work impairment, $P<0.0001 ;$ presenteeism, $P<$ 0.0001 ; absenteeism, $P=0.0073$; activity impairment, $P<0.0001$

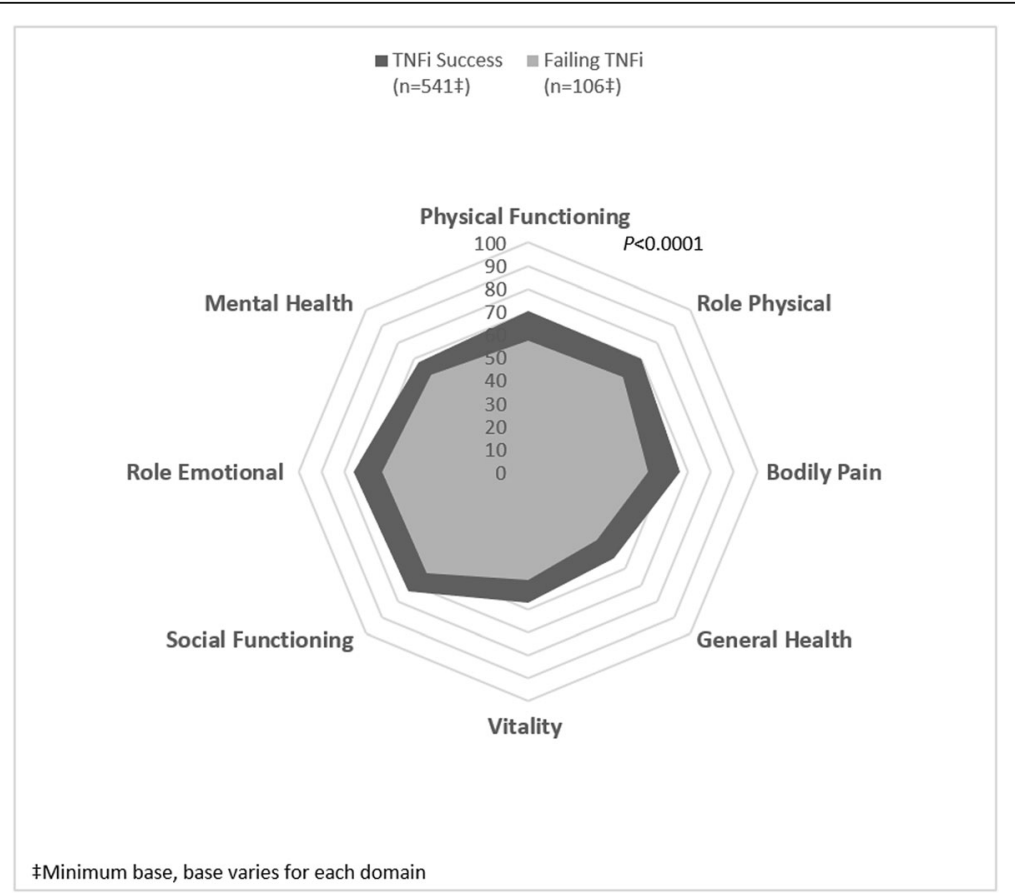

Fig. 4 Results are adjusted for age, gender, BMI, smoking status, time since symptom onset and region 
inadequate efficacy was 11 months [26]. These findings indicate that patients may be maintained on failing therapy for significantly longer than the 12 weeks recommended by ACR/SAA/SPARTAN treatment guidelines [9].

Our analyses also demonstrate that failing TNFi therapy is associated with poorer patient-reported HRQoL, as measured by EQ-5D-3 L and SF-36, as well as negative impact on daily activities measured by WPAI. Analysis of SF-36 highlighted that failing TNFi treatment is associated with poorer outcomes across all domains associated with HRQoL, despite the fact that differences between patient groups in MCS and PCS scores were not large. Future studies are needed to confirm our results and examine the clinical relevance of these findings. Although absenteeism and presenteeism are common in patients with AS, which has been shown to negatively impact HRQoL [4, 27], to the best of our knowledge, this is the first real-world study to compare HRQoL and WPAI in patients with successful vs. failing TNFi treatment. The impact of time to switch to another TNFi on HRQoL, and economic and social burden of AS, was not explored in this study but it is an area of interest for future research.

TNFi treatment failure is an important consideration in the management of AS patients, since until recently TNFi were the only approved biologic treatment for AS. Following the recent approvals of the IL-17A antagonists secukinumab and ixekizumab, the ACR/SAA/SPARTAN recommendations include switching to either [9] as they are demonstrated effective in patients with inadequate response to $\mathrm{TNFi}$, providing an option for those whose disease is not controlled by TNFi therapy [28, 29]. At the time of this study, TNFi were the only biologic therapy available, therefore the real-world clinical impact of switching to a new class of biologics such as secukinumab or ixekizumab could not be assessed and represents an important area of future research.

A major strength of this study is that it presents realworld data in patients with a clinically confirmed diagnosis of AS around the world, providing insight into rates of TNFi use and switching, as well as the negative impact on patients' HRQoL and work productivity associated with failing TNFi therapy.

Several potential limitations associated with data derived from this cross-sectional, real-world study should be considered. A primary limitation of the analysis is that the source data is a point-in time survey and does not capture the exact timepoint at which patients fail to respond to therapy, therefore it was necessary to rely on physician-reported reasons for switching therapy to identify the subset who failed to respond. Crosssectional studies are limited in their selection of patients, sample size and data collection. The high rate of patients receiving TNFi in countries where access to biologics is limited (LatAm) may be impacted by small physician and patient sample size and reflect a selection bias. In contrast to a clinical trial where disease severity and activity are assessed by validated measures, physician ratings of disease severity/activity may be considered subjective, and hence a limitation. However, our study reflects how physicians' practice in a real-world clinical setting where assessments may be more holistic rather than focusing solely on disease activity. Finally, although recall bias is a common limitation of surveys, as data were collected at the time of patients' appointments, the likelihood of recall bias is reduced.

\section{Conclusions}

In conclusion, this large multinational real-world study of AS patients demonstrated that lack or loss of efficacy of TNFi is common, yet it appears that patients failing the 1st TNFi (primary lack of efficacy/failure) are not switched to another TNFi for nearly 1 year. A significant proportion of patients who failed their 1st TNFi did not respond to subsequent TNFi. Failing TNFi therapy is associated with poorer HRQoL, physical activity and work productivity. Whether regular monitoring and earlier use of appropriate therapies upon identification of lack of efficacy leads to improvements in symptom control and HRQoL remains to be seen.

\section{Supplementary information}

Supplementary information accompanies this paper at https://doi.org/10. 1186/s41927-020-0118-z.

Additional file 1: Table S1. Patient characteristics, Description of data: Detailed patient characteristics, including disease severity and disease scores, are provided.

\section{Abbreviations}

APAC: Asia-Pacific region; AS: Ankylosing spondylitis; BASDAl: Bath ankylosing spondylitis disease activity index; bDMARD: Biological disease modifying antirheumatic drug; BMI: Body mass index; CRP: C-reactive protein; DSP: Disease Specific Program; EQ-5D-3 L: 5-dimension EuroQoL; ESR: Erythrocyte sedimentation rate; EU5: European Union 5; HLA-B27: Human leukocyte antigen B27; HRQoL: Health-related quality of life; IL-17A: interleukin-17A; IQR: Interquartile range; LatAm: Latin America; MCS: Mental component summary; PCS: Physical component summary; SD: Standard deviation; SF36v2: Short-form health survey version 2; T\&ME: Turkey and Middle East; TNFi: Tumor necrois factor inhibitor; USA: United States of America; WPAI: Work productivity and activity impairment

\section{Acknowledgments}

Medical writing support was provided by Kate Revill of Adelphi Real World Ltd., funded by Novartis Pharma AG. Additional writing support was provided by Elizabeth Holdsworth, Nicola Booth and Katerina Doslikova, employees of Adelphi Real World Ltd. PGC is supported in part by the UK NIHR Leeds Biomedical Research Centre. The views expressed in this publication are those of the author(s) and not necessarily those of the NHS, the National Institute for Health Research or the Department of Health. The authors and Novartis would like to thank all patients and physicians who participated in this study. 


\section{Authors' contributions}

ES and SB contributed to the conception, design, acquisition, analysis and interpretation of the data. AD, VS, PGC, HT, KG, SMJ and RA contributed to the conception, design, analysis and interpretation of the data. All authors read and approved the final manuscript to be published after critically revising it for important intellectual content.

\section{Funding}

This study was supported by Novartis Pharma AG, Switzerland. HT, KG and SMJ, Novartis authors, contributed to the conception, design, analysis and interpretation of the data, and read and approved the final manuscript to be published after critically revising it for important intellectual content.

\section{Availability of data and materials}

Data are owned by Adelphi Real World. All requests regarding data should be addressed directly to Adelphi Real World.

\section{Ethics approval and consent to participate}

The DSP is a non-interventional, market research project that collects retrospective data, excludes identifiable protected health information, and complies with all relevant market research guidelines and legal obligations. Data were collected in accordance with the European Pharmaceutical Marketing Research Association guidelines, the US Health Insurance Portability and Accountability Act 1996 (HIPAA;www.hhs.gov/ocr/privacy/), the Health Information Technology for Economic and Clinical Health, and all other pertinent regulations in place at the time of the data collection and thus did not require ethics committee approvals [14]

\section{Consent for publication}

Not applicable.

\section{Competing interests}

AD has received grants or research support from AbbVie, Eli Lilly, GlaxoSmithKline, Janssen, Novartis, Pfizer and UCB Pharma, and consulting fees from Eli Lilly, Janssen, Novartis, Pfizer and UCB Pharma. VS has received grants and/or consulting fees from AbbVie, Amgen, AstraZeneca, BMS, Boehringer Ingelheim, Celltrion, Corrona LLC, Crescendo Bioscience, EMD Serono, F. Hoffmann-La Roche Ltd./Genentech, Inc., GSK, Janssen, Eli Lilly, Merck, Novartis, Pfizer, Regeneron, Samsung, Sandoz, Sanofi and UCB, and has served on advisory boards for AbbVie, Amgen, AstraZeneca, BMS, Celltrion, Crescendo/Myriad Genetics, EMDSerono, Genentech/Roche, GSK, Janssen, Lilly, Novartis, Pfizer, Regeneron, Sandoz, Sanofi and UCB. PGC has received speakers' bureau or consulting fees from Bristol- Myers Squibb, Pfizer and Novartis. RA has received grants or research support from BristolMyers Squibb, consulting fees from Bristol-Myers Squibb, Novartis, Pfizer Roche and Eli Lilly. ES \& SB are employees of Adelphi Real World; HT and KG are shareholders and employees of Novartis; $\mathrm{S} J$ is a shareholder and employee of Novartis Pharma AG.

\section{Author details}

'Oregon Health and Science University, Portland, OR, USA. ${ }^{2}$ Biopharmaceutical Consultant, Portola Valley, CA, USA. ${ }^{3}$ Leeds Institute of Rheumatic and Musculoskeletal Medicine, University of Leeds \& NIHR Leeds Biomedical Research Centre, Leeds, UK. ${ }^{4}$ Adelphi Real World, Bollington, UK. ${ }^{5}$ Novartis Pharmaceuticals Corporation, East Hanover, NJ, USA. ${ }^{6}$ Novartis Pharma AG, Basel, Switzerland. ' Schlosspark-Klinik, University Medicine, Berlin, Germany.

Received: 29 January 2020 Accepted: 5 February 2020 Published online: 02 March 2020

\section{References}

1. Dean LE, Jones GT, MacDonald AG, Downham C, Sturrock RD, Macfarlane GJ. Global prevalence of ankylosing spondylitis. Rheumatology (Oxford). 2014:53(4):650-7.

2. Salaffi F, Carotti M, Gasparini S, Intorcia M, Grassi W. The health-related quality of life in rheumatoid arthritis, ankylosing spondylitis, and psoriatic arthritis: a comparison with a selected sample of healthy people. Health Oual Life Outcomes. 2009:7.25.

3. Braun J, Sieper J. Ankylosing spondylitis. Lancet. 2007;369(9570):1379-90
4. Boonen A, Boone C, Albert A, Mielants H. Understanding limitations in atwork productivity in patients with active ankylosing spondylitis: the role of work-related contextual factors. J Rheumatol. 2015;42(1):93-100.

5. Deodhar A, Mease PJ, Reveille JD, Curtis JR, Chen S, Malhotra K, et al. Frequency of axial Spondyloarthritis diagnosis among patients seen by US rheumatologists for evaluation of chronic Back pain. Arthritis Rheumatol. 2016;68(7):1669-76.

6. Akgul O, Ozgocmen S. Classification criteria for spondyloarthropathies. World J Orthop. 2011;2(12):107-15.

7. Almodovar R, Font P, Zarco-Montejo P, Collantes E, Mulero J, Gratacos J, et al. Phenotypic differences between familial versus sporadic ankylosing spondylitis: a cross-sectional Spanish registry of spondyloarthropathies (REGISPONSER). Clin Exp Rheumatol. 2011;29(5):822-7.

8. Salvadorini G, Bandinelli F, Delle Sedie A, Riente L, Candelieri A, Generini S, et al. Ankylosing spondylitis: how diagnostic and therapeutic delay have changed over the last six decades. Clin Exp Rheumatol. 2012;30(4):561-5.

9. Ward MM, Deodhar A, Gensler LS, et al. 2019 Update of the American College of Rheumatology/spondylitis Association of America/ Spondyloarthritis research and treatment network recommendations for the treatment of Ankylosing spondylitis and nonradiographic axial Spondyloarthritis. Arthritis Rheumatol. 2019:0(0).

10. Heiberg MS, Koldingsnes W, Mikkelsen K, Rodevand E, Kaufmann C, Mowinckel $P$, et al. The comparative one-year performance of anti-tumor necrosis factor alpha drugs in patients with rheumatoid arthritis, psoriatic arthritis, and ankylosing spondylitis: results from a longitudinal, observational, multicenter study. Arthritis Rheum. 2008;59(2):234-40.

11. Anderson P, Benford M, Harris N, Karavali M, Piercy J. Real-world physician and patient behaviour across countries: disease-specific Programmes - a means to understand. Curr Med Res Opin. 2008;24(11):3063-72.

12. Services UDoHaH. Summary of the HIPAA Privacy Rule 2003 [Available from: http://www.hhs.gov/sites/default/files/privacysummary.pdf.

13. Technology HI. Health Information Technology Act [Available from: https://www.healthit.gov/sites/default/files/hitech_act_excerpt_from_arra_ with_index.pdf.

14. Association EPMR. European Pharmaceutical Market Research Association (EphMRA) Code of Conduct 2017 [updated January 2017. European Pharmaceutical Market Research Association (EphMRA) Code of Conduct Updated January 2017]. Available from: http://www.ephmra.org/Code-ofConduct-Support.

15. EuroQol G. EuroQol--a new facility for the measurement of health-related quality of life. Health Policy. 1990;16(3):199-208.

16. Dolan P. Modeling valuations for EuroQol health states. Med Care. 1997; 35(11):1095-108

17. Ware JE Jr, Sherbourne CD. The MOS 36-item short-form health survey (SF-36). I. Conceptual framework and item selection. Med Care. 1992; 30(6):473-83.

18. Ware J. User's manual for the SF-36v2 ${ }^{\oplus}$ health survey: Lincoln (RI); 2007.

19. Reilly MC, Zbrozek AS, Dukes EM. The validity and reproducibility of a work productivity and activity impairment instrument. Pharmacoeconomics. 1993; 4(5):353-65

20. Heinonen AV, Aaltonen KJ, Joensuu JT, Lahteenmaki JP, Pertovaara MI Romu MK, et al. Effectiveness and drug survival of TNF inhibitors in the treatment of Ankylosing spondylitis: a prospective cohort study. J Rheumatol. 2015:42(12):2339-46.

21. Ciurea A, Exer P, Weber U, Tamborrini G, Steininger B, Kissling RO, et al. Does the reason for discontinuation of a first TNF inhibitor influence the effectiveness of a second TNF inhibitor in axial spondyloarthritis? Results from the Swiss Clinical Quality Management Cohort. Arthritis Res Ther. 2016;18:71.

22. Coates LC, Cawkwell LS, Ng NW, Bennett AN, Bryer DJ, Fraser AD, et al. Real life experience confirms sustained response to long-term biologics and switching in ankylosing spondylitis. Rheumatology (Oxford). 2008; 47(6):897-900.

23. Lie E, van der Heijde D, Uhlig T, Mikkelsen K, Rodevand E, Koldingsnes $W$, et al. Effectiveness of switching between TNF inhibitors in ankylosing spondylitis: data from the NOR-DMARD register. Ann Rheum Dis. 2011;70(1):157-63.

24. Plasencia C, Pascual-Salcedo D, Garcia-Carazo S, Lojo L, Nuno L, Villalba A et al. The immunogenicity to the first anti-TNF therapy determines the outcome of switching to a second anti-TNF therapy in spondyloarthritis patients. Arthritis Res Ther. 2013;15(4):R79. 
25. Deodhar Atul YD. Switching tumor necrosis factor inhibitors in the treatment of axial Spondyloarthritis. Seminars Arthritis Rheumatism. 2017; 47(3):343-350

26. Pradeep DJ, Keat AC, Gaffney K, Brooksby A, Leeder J, Harris C. Switching anti-TNF therapy in ankylosing spondylitis. Rheumatology (Oxford). 2008; 47(11):1726-7.

27. Yang X, Fan D, Xia Q, Wang M, Zhang X, Li X, et al. The health-related quality of life of ankylosing spondylitis patients assessed by SF-36: a systematic review and meta-analysis. Qual Life Res. 2016;25(11):2711-23.

28. Marzo-Ortega H, Sieper J, Kivitz A, Blanco R, Cohen M, Martin R, et al. Secukinumab sustains improvement in signs and symptoms of patients with active ankylosing spondylitis through 2 years: results from a phase 3 study. Arthritis Care Res (Hoboken). 2017;69(7):1020-29.

29. Baeten D, Sieper J, Braun J, Baraliakos X, Dougados M, Emery P, et al. Secukinumab, an interleukin-17A inhibitor, in Ankylosing spondylitis. N Engl J Med. 2015;373(26):2534-48.

\section{Publisher's Note}

Springer Nature remains neutral with regard to jurisdictional claims in published maps and institutional affiliations.

Ready to submit your research? Choose BMC and benefit from:

- fast, convenient online submission

- thorough peer review by experienced researchers in your field

- rapid publication on acceptance

- support for research data, including large and complex data types

- gold Open Access which fosters wider collaboration and increased citations

- maximum visibility for your research: over $100 \mathrm{M}$ website views per year

At BMC, research is always in progress.

Learn more biomedcentral.com/submissions 